Editorial

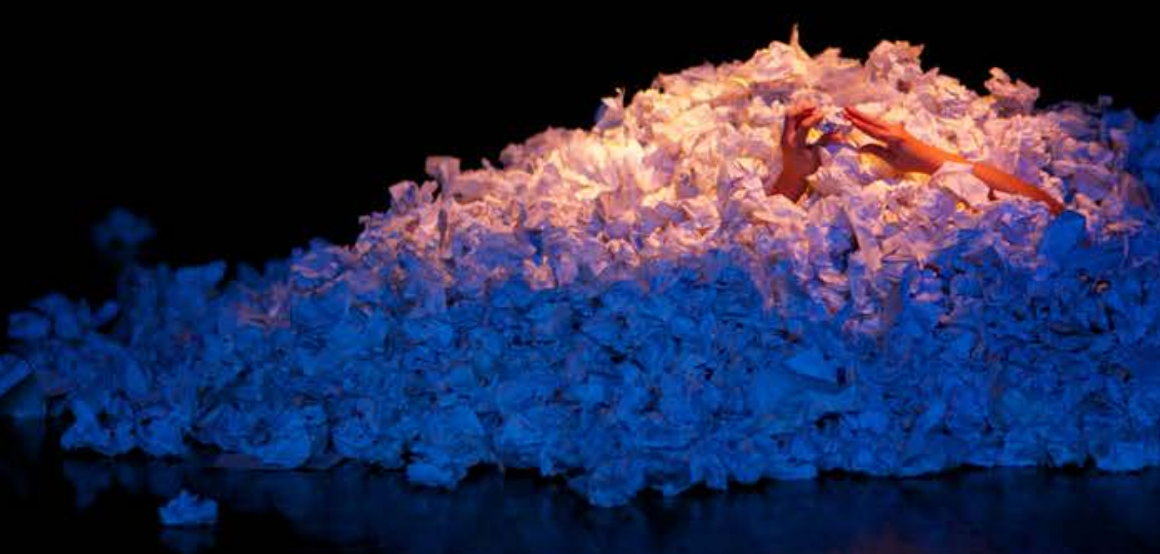




\section{Carta a los autores y convocatoria permanente}

\author{
Pedro Pablo Gómez Moreno \\ Editor \\ Universidad Distrital Francisco José de Caldas, \\ Colombia \\ ppgomezm@udistrital.edu.co
}

Cómo citar este articulo: Gómez Moreno, Pedro Pablo (2020). Carta a los autores y convocatoria permanente. Estudios Artísticos: revista de investigación creadora, 6(9). pp. 174-177. DOI: https://doi. org/10.14483/25009311.16506

La Factoría (2012). Danza IV año, énfasis interpretación. Facultad de Artes ASAB. Fotografía: Carlos Mario Lema.

\section{(c) (7)}

https://creativecommons.org/licenses/by/4.0/deed.es
De vez en cuando es necesario recordar a los investigadores y creadores, interesados en publicar en Estudios Artísticos: revista de investigación creadora, los términos generales de la política editorial que guía nuestras actividades de socialización de conocimientos sensibles producidos en los campos de las artes y las culturas.

Estudios Artísticos: revista de investigación creadora es un medio de circulación de saberes y conocimientos producidos por las comunidades inter-epistémicas del campo emergente de los estudios artísticos. Como medio de comunicación facilita la construcción de comunidades artísticas, disciplinares, interdisciplinares y transdisciplinares, así como redes de investigadores en el ámbito nacional e internacional. Ante todo, propende por la apropiación social de las diversas formas del conocimiento como medio para transformación de sujetos y colectividades.

Desde su primera publicación en el año 2015, Estudios Artísticos realiza su proceso de revisión y publicación de artículos sin costo alguno para el autor. Cualquier autor, sin importar su nacionalidad, puede enviar sus artículos a través del sistema OJS de la revista para iniciar el proceso de evaluación. Cuando este proceso culmine y en caso de ser aprobado el artículo será publicado. 
Nuestro público objetivo está constituido especialmente por docentes, investigadores, estudiantes y profesionales interesados en la actualización permanente de sus conocimientos y el seguimiento de los procesos de investigacióncreación en el campo del arte y los estudios artísticos. Así mismo, nuestra misión consiste en divulgar resultados de proyectos de investigacióncreación realizados en el campo del arte y los estudios artísticos, a través de la publicación de artículos originales e inéditos, realizados por académicos artistas y profesionales pertenecientes a instituciones nacionales o extranieras del sector público o privado.

Editada por La Universidad Distrital Francisco José de Caldas, Estudios Artísticos tiene alcance geográfico en América Latina, El Caribe y España, sin cerrar su potencial de circulación en contextos más amplios. Es una revista con una periodicidad semestral que publica en varios idiomas un conjunto de artículos agrupados en diferentes secciones de acuerdo con su tipología.

Como toda revista académica, nuestra publicación aclara a los autores la forma de presentación de los artículos, los cuales sin excepción deben ser enviados a través de la plataforma OJS de la revista: (http://revistas.udistrital.edu.co/ojs/index.php/ estart) realizando el correspondiente registro del autor. De esta manera, será posible para los autores hacer el seguimiento al proceso de evaluación y edición de sus artículos.

Un aspecto muy importante de nuestra política editorial tiene que ver con los derechos de los autores. Para tal fin, trabajamos con una licencia Creative Commons Reconocimiento-No comercialSin obras derivadas 4.0 Colombia, donde se le garantiza al autor el reconocimiento de los créditos por su trabajo y autoría. La revista no altera, ni transforma o genera una obra a partir del artículo. Adicional a ello se garantiza al autor que no se utilizará su artículo para fines comerciales. Todo esto en concordancia con la política de acceso abierto de la revista.

Por su parte, los criterios y procedimientos de evaluación de los artículos son muy claros: todos los artículos son sometidos a un proceso de arbitraje anónimo, llevado a cabo por evaluadores nacionales o extranjeros que podrán hacer sugerencias al autor. El autor debe tener en cuenta las observaciones de los revisores, del editor o del Comité Editorial de la revista para realizar los ajustes necesarios. El Comité Editorial decide a propuesta del editor de la publicación de los artículos aprobados en el número correspondiente. Estudios Artísticos se reserva el derecho de introducir los cambios formales necesarios para adaptar el texto a los estándares de publicación.

Nuestras acciones están guiadas por un política de buenas prácticas, ética de la investigación y respeto a las culturas y al patrimonio.

Estos aspectos generales que hemos resumido aquí, forman parte de la Guía para autores que está disponible al final de la versión impresa de la revista tanto en español como en inglés y en un lugar visible en el sitio web de Estudios Artísticos. Cuando un autor envía un artículo a la revista, tal y como se expresa en el numeral XIV de la mencionada guía, acepta las condiciones allí expresadas.

Por todo lo anterior, exhortamos a los autores, a leer cuidadosamente la mencionada guía antes de realizar los envíos de sus contribuciones, resultados de sus prácticas de investigación y creación, teniendo en cuenta que la convocatoria es permanente y los artículos se publican en estricto orden de aprobación. 